\section{Research Square}

\title{
Improving oral hygiene may attenuate occurrence of head and neck cancer: nation-wide population based cohort study.
}

Ho Geol Woo

Ewha Women's University College of Medicine

Kijeong Lee

Eunpyeong St. Mary's Hospital, Catholic University of Korea

Ji Sung Lee

Asan Medical Center

Jinkwon Kim

Gangnam Severance Hospital

Younkyung Chang

Ewha Women's University College of Medicine

Jin-Woo Kim

Ewha Women's University College of Medicine

Tae Jin Song ( $\sim$ knstar@ewha.ac.kr)

Ewha Women's University College of Medicine https://orcid.org/0000-0002-9937-762X

Research article

Keywords: Oral hygiene, Oral cancer, Head and neck cancer, Tooth brushing, General population, Longitudinal study

Posted Date: March 25th, 2020

DOI: https://doi.org/10.21203/rs.3.rs-18434/v1

License: (a) (1) This work is licensed under a Creative Commons Attribution 4.0 International License. Read Full License 


\section{Abstract}

Background: In previous case-control and cross-sectional studies, less frequent dental visits, infrequent tooth brushing, presence of periodontal disease, and increased number of tooth loss were shown to be associated with increased risk of head and neck cancer. However, studies regarding the association of periodontal disease and parameters of oral health with occurrence of head and neck cancer have been lacking particularly in longitudinal setting. We aimed to investigate the relationship between parameters of oral health and risk of head and neck cancer in a nationwide general population-based cohort.

Methods : We included 150,774 subjects from the Korean National Health Insurance System-Health Screening Cohort for demographics, past history, and laboratory findings. The presence of periodontal disease and parameters of oral health including frequency of tooth brushings, dental visit for any reason, expertised dental cleaning, and number of tooth loss were investigated. Head and neck cancer was defined as International Statistical Classification of Diseases-10 codes of 'C00-C14'.

Results: During median 11.1 years of follow-up, 1,155 (0.76\%) head and neck cancers occurred. Based on multivariable analysis, after adjusting for demographics, alcohol intake, smoking, regular exercise, body mass index, systolic blood pressure, blood and urinary laboratory findings, and parameters of oral health, frequent tooth brushing (more than three times per day) was related to lower risk of head and neck cancer (hazard ratio, HR: $0.78,95 \%$ confidence interval, $\mathrm{Cl}$ : $0.66-0.93, p=0.005$ ). Increased number of tooth loss was positively associated with occurrence of head and neck cancer ( $p$ value for trend test for HR $<0.001$ ).

Conclusions : The occurrence of head and neck cancer was decreased with the more frequent tooth brushing (more than three times per day) and increased with the number of tooth loss. In regards of head and neck cancer prevention, improving oral hygiene may have significant contribution.

\section{Background}

Primary head and neck cancers, such as malignancies in the oral cavity, larynx, hypopharynx, and oropharynx, are emerging and troublesome diseases worldwide [1]. Although recent advances in medicine have improved survival rates, the prognosis of head and neck cancer remains poor [2]. Therefore, identifying and controlling the risk factors or causative factors of head and neck cancer is important. To date, although risk factors such as human papillomavirus (HPV) infection, smoking, and alcohol intake were demonstrated [3], there is unknown part about information regarding other risk factors or related factors, which need additional research.

Periodontal disease is closely associated with oral hygiene [4]. Moreover, parameters of oral health such as number of tooth loss, frequency of tooth brushings, and expertised dental cleaning are related to oral hygiene [5-7]. In previous study, insufficient oral sanitation can induce temporary bacteremia or systemic inflammation, and this inflammatory process is a well-known mediator of cancer [8,9]. Moreover, periodontitis, which is more severe form of periodontal disease, cause inflammation of periodontal ligament, alveolar bone, and gingiva, resulting in tooth loss and systemic inflammation [10,11]. Chronic 
inflammatory reaction due to insufficient oral hygiene and periodontal disease lead oral bacteria to invade gingival epithelial cells, avoid the immune system of the host, and inhibit apoptosis, resulting in development of malignancy [12-14].

Recently, studies regarding a relation between parameters of oral health and risk of head and neck cancer are evolving. Previous studies reported that poor oral health, loss of multiple teeth, and infrequent tooth brushing are related to the risk of upper aerodigestive tract cancers including in the lips, oral cavity, oropharynx, hypopharynx, larynx, and esophagus $[15,16]$. Moreover, other case-control and crosssectional studies, less frequent dental visits, having periodontal disease, infrequent tooth brushing, and large number of tooth loss were shown to be associated with increased risk of head and neck cancer [17, 18]. Recent one meta-analysis showed that infrequent dental visits was increased in head and neck cancer patients [19]. However, studies about the relationship between parameters of oral health and periodontal disease and occurrence of head and neck cancer are sparse in longitudinal setting.

We hypothesized the better oral hygiene would decrease risk of head and neck cancer in a longitudinal study setting. The present study was assessed in a nationwide general population-based cohort to investigate the relation between parameters of oral health and the occurrence of head and neck cancer.

\section{Methods}

\section{Database}

The National Health Insurance System (NHIS) includes demographics, kinds of covered health insurance, socioeconomic status, database for treatment and diagnosis modalities, and database of medical care institution and a nationwide-supported health examination. This system consists of health information from random sampling of 50 million Koreans [20]. It is the only one insurance provider, provided by the government of Korean. A total of $97 \%$ and $3 \%$ of the Korean population are provided by the NHIS and the Medical Aid program, respectively. Biannually, members of the system are advised to perform uniformed health examinations from 2002 years [21]. Subjects from the NHIS-Health Screening Cohort (NHISHEALS) were enrolled in the present study [22]. The screening program of oral health in NHIS is provided to subscribers $\geq 40$ years of age. The program consists of self-reported surveys including information regarding dental symptoms, oral hygiene behavior, and dental visits during the last year. Subjects are checked by dentists for status of oral health including the number of tooth loss. If oral health is poor, oral hygiene practice is advised to the participants if necessary [23].

\section{Study population}

The present study was evaluated on 2003 2004 data from the cohort and included adult subjects 40-79 years of age. In order to rule out the possibility of hidden malignancy, the study was conducted with datasets from 2003 to 2004, taking into account the washout period of one more years from 2003. Among 514,866 total participants, those who had missing data in oral health status $(n=343,037)$, in 
health examination $(n=8,094)$, or previous history of any malignancy $(n=12,961)$ were excluded. Finally, the complete case dataset of 150,774 subjects were investigated in present study (Fig. 1).

\section{Study variables and definitions}

The definition of comorbidity is described in the Supplementary file (Additional file 1). Presence of periodontal disease was defined as when both International Statistical Classification of Diseases-10 (ICD10 ) codes (acute periodontitis (K052), chronic periodontitis (K053), periodontosis (K054), other periodontal disease (K055), and unspecified periodontal disease (K056)) were claimed two or more times by dentist or when subjects were treated periodontal disease (ICD-10 codes K052-56) by dentist based on previous studies [23-25]. Oral hygiene behaviors (expertised dental cleaning, dental visit for any reason, and the frequency of tooth brushings) were acquired from self-reported survey of oral health examination [23]. Frequency of tooth brushings was categorized (more than three times per day, twice per day, and none or one time per day). Expertised dental cleaning and dental visit for any reason were dichotomized (at least one time per year or never). If the subject received expertised dental cleaning or dental visit once every two years, the subject was classified into never group. The number of tooth loss were checked by dentists for oral health examination [23]. The number of tooth loss was classified regardless of the causes $(\geq 15,8-14,1-7$, and 0$)$. The index date was indicated as the date on examination for the status of oral health. If two or more examinations for oral health were taken between 2003 and 2004, the most recent examination were used for the analysis. The main study outcome was the occurrence of head and neck cancer, which was defined as the presence of ICD-10 codes at least once in the medical treatment database. The ICD-10 code of head and neck cancer was defined as $\mathrm{C00}-\mathrm{C} 14$ based on previous studies (C00-C06, oral cavity, oral cancer; $\mathrm{C} 07-\mathrm{C} 08$, salivary gland cancer; $\mathrm{C} 09-\mathrm{C} 14$, tonsil and pharynx cancer) $[18,26]$. Subjects with a diagnosis of head and neck cancer before the index date were excluded. Diagnosis using ICD-10 codes has already been validated by comparison with the Korean National Cancer Incidence Database. The overall sensitivity of cancer diagnosis using the ICD-10 codes was $92.8 \%$ [27].

\section{Statistical analyses}

The Chi-square test and independent $t$-test were conducted to compare categorical and continuous variables, respectively. To compare demographic data of included subjects with that of excluded subjects, because there is a possibility of false positive in large sample size data from Chi-square test and independent t-test, we investigated standardized difference. If the standardized difference is greater than 0.1 with absolute value, it is considered that there is a difference between included subjects and excluded subjects. The cumulative incidence curves analyses by Gray's Test were conducted to evaluate the relationship of periodontal disease and parameters of oral health with incidence of head and neck cancer.

Using regression methods of Fine and Gray for competing risk data (death was a competing event for head and neck cancer) were utilized. Hazard ratios (HR) and 95\% confidence intervals (Cl) were calculated. Multivariable regression models were performed with adjustment for confounding factors which are age, sex, income level, alcohol intake, smoking, body mass index, regular exercise, 
hypertension, diabetes mellitus, and dyslipidemia in model 1; variables in model 1 as well as systolic blood pressure, laboratory finding in urine and blood in model 2; variables in model 2 as well as frequency of tooth brushing, periodontal disease, expertised dental cleaning, dental visit for any reason, and number of tooth loss in model 3. To investigate trend for HR of number of tooth brushing and tooth loss, $p$ value for trend was estimated. The sensitivity analyses were performed in subjects without alcohol intaken and non-smokers. The subgroup analysis according to location of head and neck caner (1. oral cavity or oral cancer; 2 . salivary gland cancer; 3 . tonsil or pharynx cancer) were investigated by a two-sided Wald test in the regression methods of Fine and Gray for competing risk data. All statistical analyses were performed using SAS software (version 9.2, SAS Institute, Cary, NC, USA). A $p$-value $<0.05$ was considered statistically significant.

\section{Results}

When comparing demographics, elderly people, women and subjects with lower income level were more frequently observed in excluded subjects (Table S1). The mean \pm standard deviation age of participants was $52.2 \pm 8.7$ years; $60.9 \%$ were males, $39.3 \%$ had hypertension, $9.0 \%$ had diabetes mellitus, and $25.3 \%$ were current smokers. Approximately $13.1 \%$ and $24.1 \%$ of included subjects had periodontal disease and one or more tooth loss, respectively. Based on self-reported survey, $40.6 \%$ of the participants brushed teeth with $\geq 3$ times/day. Approximately $23.8 \%$ of subjects had at least once expertised dental cleaning per year (Table 1).

After a median 11.1 years of follow-up, 1,155 head and neck cancers had occurred. The estimated 10year event rate for head and neck cancer was $0.76 \%$. The cumulative incidence curves for head and neck cancer are presented in Fig. 2 based on frequency of tooth brushing, expertised dental cleaning, dental visit for any reason, and number of tooth loss. The risk of head and neck cancer was lower when a subject had better oral hygiene, for example frequent tooth brushing, frequent dental visits, and expertised dental cleaning. In contrast, poor oral health status including a greater number of tooth loss was associated with a higher risk of head and neck cancer.

Based on multivariable regression, frequent tooth brushing (more than three times per day) was significantly associated with lower risk of head and neck cancer (HR: $0.75,95 \% \mathrm{Cl}: 0.64-0.89, \mathrm{p}=0.001, \mathrm{p}$ for trend $<0.001$ in model 1; HR: $0.76,95 \% \mathrm{Cl}: 0.64-0.90, p=0.002, p$ for trend $=0.001$ in model 2; HR: 0.79, $95 \% \mathrm{Cl}: 0.66-0.94, p=0.007, p$ for trend $=0.005$ in model 3 ) (Table 2 ). Increased number of tooth loss was positively related to occurrence of head and neck cancer based on multivariable analysis $(p<0.001$ in model 1,2, and 3). More than 15 tooth loss was positively associated with risk of head and neck cancer (HR: 1.71, 95\% Cl: 1.26-2.31, $p=0.001$ in model 1; HR: 1.68, 95\% Cl: 1.24-2.28, $p<0.001$ in model 2; HR: $1.66,95 \% \mathrm{Cl}: 1.22-2.25, \mathrm{p}=0.001$ in model 3 ) (Table 2). However, adjusting for confounding factors, the statistical significance of the relation between expertised dental cleaning and dental visit for any reason and future occurrence risk of head and neck cancer was diminished in models 1-3 (Table 2). 
In sensitivity analyses, the association of frequent tooth brushing and number of tooth loss with occurrence risk of head and neck cancer was consistently noted in subjects without alcohol intake and non-smokers (Table S2 and S3). In subgroup analysis, the relationship of frequent tooth brushing and number of tooth loss with occurrence risk of head and neck cancer was consistently noted in oral cavity or oral cancer (Table S4). The number of tooth loss $(\geq 15)$ was associated with future occurrence risk of salivary gland cancer (Table S5). In contrast, periodontal disease and parameters of oral health were not related to occurrence of tonsil or pharynx cancer (Table S6).

\section{Discussion}

Our findings from the present study are frequent tooth brushing may lower the occurrence of head and neck cancer even after adjusting for important confounding factors. In addition, poor oral health evidenced by a greater number of tooth loss was independently related to future occurrence of head and neck cancer.

In previous studies, infrequent tooth brushing was associated with head and neck malignancies, particularly in tongue, gum, and other areas of the mouth $[6,28,29]$. Tooth brushing less than once a day was also associated with risk of tongue cancer (odds ratio: 2.1) and cancer in other parts of the mouth (odds ratio: 2.4) [30]. In a case-control study of Chinese subjects, the risk of oral cancer was 6.9-fold greater for males and 2.5-fold for females in subjects who infrequently brushed their teeth [31]. Results in another European study indicated daily brushing was a protective factor against developing oral cancer (odds ratio: 0.41) [32]. The results from the present study are in agreement with the above-mentioned studies and provide additional information for longitudinal relationship of tooth brushing with decreased occurrence of head and neck cancer.

In the present study, a positive association between loss of multiple teeth and the occurrence of head and neck cancer was observed. These association has been consistently reported in previous studies. In a meta-analysis of case-control and cross-sectional studies, the odds ratio for tooth loss more than 5 of head and neck malignancy was 2.0 [33]. In addition, in a dose-response meta-analysis of prospective cohort studies, tooth loss was significantly related to a higher occurrence of head and neck cancer [34]. Tooth loss may be closely related to failure of maintaining oral hygiene (infrequent tooth brushing, dental visits, and expertised dental cleaning), exposure to cancer-inducing factors such as smoking, nitrosamines, or alcohol, and secondary inflammation or infection of the oral cavity $[35,36]$. Because these factors may promote malignancy [37, 38], our hypothesis is plausible.

To investigate of which site head and neck cancer is more associated with oral hygiene, we analyzed the site specific risk according to oral disease and hygiene. For the oral cavity cancers, the results were quite similar to the main result of present study. On the other hand, for the tonsil or pharynx cancer, risk of cancer occurrence was not associated with oral health and oral hygiene, statistically significantly. This result seems supportive of the hypothesis that, poor oral hygiene can mediate cancer mainly in oral cavity. 
In the present study, visiting the dentist and expertised dental cleaning were associated with decreased occurrence of head and neck cancer. However, infrequent dental visits was related to an increased occurrence of head and neck cancer based on univariable analysis. These results are consistent with previous studies $[6,7,39,40]$. Conversely, after adjusting for various important confounding factors, the association between dental visits and expertised dental cleaning and occurrence of malignancy was not statistically significant. These results may be due to other factors, which are more likely associated with malignancy than dental visits and expertised dental cleaning.

Paradoxically, the presence of periodontal disease was decreased occurrence of head and neck cancer. Subjects with periodontal disease visit hospitals more often than subjects without periodontal disease and receive more frequent health care. Moreover, in our study, definition of periodontal disease using the ICD-10 code does not apply recently published classification criteria and definitions of case for periodontal disease [41]. In addition, the discrepancy of age, sex, income level between the included subjects and excluded those may explain these results.

The present study had several limitations. First, although this was a longitudinal study and the cohort was retrospectively analyzed without intervention, therefore, the information bias could not be excluded and causal relationships were not confirmative. Second, many subjects were excluded before analysis due to the missing value in the oral health status data. Because the oral examination was not a mandatory test item, this exclusion may lead to a selection bias, leaving the subjects with healthier behavior in the study dataset. Third, although we used a wash-out period of one year before the index date, a hidden malignancy at baseline remains a possibility. Fourth, the frequency of tooth brushings and expertised dental cleanings were assessed based on a self-reported survey, which may be subject to recall bias. Fifth, although parameters of oral health can be altered during follow up, our study did not take into account these time-varying factors. Sixth, although HPV infection and their treatment were important covariates for occurrence of head and neck cancer, because treatment for HPV infections was not covered by national insurance, our health claim data could not adjust the HPV-related parameters. Seventh, the NHIS-HEALS cohort dataset does not supply information about the education or occupations of the subjects. Therefore, income level was the only adjusted variable that reflects socioeconomic status. Finally, because this is a cohort study with a large number of subjects without a sample-size calculation, we cannot completely rule out the possibility that the association between oral health and the occurrence of head and neck cancer is statistically significant only due to the large sample size.

Nevertheless, the present study had several strengths. Contrary to previous studies, which were mostly case-control studies, this was a nationwide, general population-based longitudinal study. In addition, this study included a relatively large sample size. Distinct from previous studies, various risk factors were included such as comorbidities, laboratory findings, alcohol intake, smoking status, and oral hygiene, and adjusted in multivariable analysis in this study.

\section{Conclusions}


The better oral hygiene behavior, particularly brushing teeth $\geq 3$ times a day, was associated with a reduced risk of head and neck cancer. Poor oral hygiene, especially the greater number of tooth loss, was increased risk of head and neck cancer. Therefore, improving oral hygiene may have significant contribution to lower the risk of head and neck cancer.

\section{Abbreviations}

Human papillomavirus

HPV

National Health Insurance System

NHIS

National Health Insurance System-Health Screening Cohort

NHIS-HEALS

International Statistical Classification of Diseases and Related Health Problems

ICD

Hazard ratio

HR

Confidence interval

$\mathrm{Cl}$

\section{Declarations}

\section{Ethics approval and consent to participate}

Our study was approved by Institutional Review Board of the Ewha Womans University of College of Medicine (EUMC 2018-01-067); Because of the retrospective anonymized dataset, written informed consent from participants was waived.

\section{Consent for publication}

Not applicable

\section{Availability of data and materials}

The data that support the findings of this study are available from NHIS-HEALS, but restrictions apply to the availability of these data, which were used under license for the current study and so are not publicly available. Data are, however, available from the authors upon reasonable request and with permission from the National Health Insurance System.

\section{Competing interests}

The authors declare that they have no competing interests 


\section{Source of funding}

This work was supported by a grant from the Basic Science Research Program through the National Research Foundation of Korea funded by the Ministry of Education (2018R1D1A1B07040959).

\section{Authors' contributions}

H.G.W. is expected to have made substantial contributions to the conceptualization, methodology, software, investigation, resources, data curation, writing (original draft preparation), writing (review and editing), visualization. K.L. is expected to have made substantial contributions to the conceptualization, methodology, software, formal analysis, investigation, resources, writing (original draft preparation), writing (review and editing), visualization. J.S.L. is expected to have made substantial contributions to the conceptualization, methodology, software, formal analysis, investigation, resources, data curation, writing (original draft preparation), visualization. J.K. is expected to have made substantial contributions to the conceptualization, methodology, software, investigation, resources, data curation, writing (review and editing), visualization. Y.C. is expected to have made substantial contributions to the conceptualization, methodology, software, validation, investigation, writing (review and editing), visualization, supervision. J.W.K. is expected to have made substantial contributions to the conceptualization, methodology, software, validation, investigation, writing (review and editing), visualization, supervision. T.J.S is expected to have made substantial contributions to the conceptualization, methodology, software, validation, formal analysis, investigation, resources, data curation, writing (original draft preparation), writing (review and editing), visualization, supervision, project administration, funding acquisition.

\section{Acknowledgements}

Not applicable

\section{References}

1. Global Burden of Disease Cancer C, Fitzmaurice C, Allen C, Barber RM, Barregard L, Bhutta ZA, Brenner H, Dicker DJ, Chimed-Orchir O, Dandona R et al: Global, Regional, and National Cancer Incidence, Mortality, Years of Life Lost, Years Lived With Disability, and Disability-Adjusted Life-years for 32 Cancer Groups, 1990 to 2015: A Systematic Analysis for the Global Burden of Disease Study. JAMA Oncol 2017, 3(4):524-548.

2. Thompson AR, Krouse RS: Terminal care in head and neck cancer patients: a framework for medical decision making. J Am Coll Surg 2004, 198(5):837-841.

3. Shaw R, Beasley N: Aetiology and risk factors for head and neck cancer: United Kingdom National Multidisciplinary Guidelines. J Laryngol Otol 2016, 130(S2):S9-S12.

4. Marcenes W, Kassebaum NJ, Bernabe E, Flaxman A, Naghavi M, Lopez A, Murray CJ: Global burden of oral conditions in 1990-2010: a systematic analysis. J Dent Res 2013, 92(7):592-597. 
5. Lissowska J, Pilarska A, Pilarski P, Samolczyk-Wanyura D, Piekarczyk J, Bardin-Mikollajczak A, Zatonski W, Herrero R, Munoz N, Franceschi S: Smoking, alcohol, diet, dentition and sexual practices in the epidemiology of oral cancer in Poland. Eur J Cancer Prev 2003, 12(1):25-33.

6. Chang JS, Lo HI, Wong TY, Huang CC, Lee WT, Tsai ST, Chen KC, Yen CJ, Wu YH, Hsueh WT et al: Investigating the association between oral hygiene and head and neck cancer. Oral Oncol 2013, 49(10):1010-1017.

7. Guha N, Boffetta P, Wunsch Filho V, Eluf Neto J, Shangina O, Zaridze D, Curado MP, Koifman S, Matos $\mathrm{E}$, Menezes A et al: Oral health and risk of squamous cell carcinoma of the head and neck and esophagus: results of two multicentric case-control studies. Am J Epidemiol 2007, 166(10):11591173.

8. Deng T, Lyon CJ, Bergin S, Caligiuri MA, Hsueh WA: Obesity, Inflammation, and Cancer. Annu Rev Pathol 2016, 11:421-449.

9. Roxburgh CS, McMillan DC: Cancer and systemic inflammation: treat the tumour and treat the host. Br J Cancer 2014, 110(6):1409-1412.

10. Kinane DF, Stathopoulou PG, Papapanou PN: Periodontal diseases. Nat Rev Dis Primers 2017, 3:17038.

11. Kassebaum NJ, Smith AGC, Bernabe E, Fleming TD, Reynolds AE, Vos T, Murray CJL, Marcenes W, Collaborators GBDOH: Global, Regional, and National Prevalence, Incidence, and Disability-Adjusted Life Years for Oral Conditions for 195 Countries, 1990-2015: A Systematic Analysis for the Global Burden of Diseases, Injuries, and Risk Factors. J Dent Res 2017, 96(4):380-387.

12. Chapple IL, Genco R, Working group 2 of joint EFPAAPw: Diabetes and periodontal diseases: consensus report of the Joint EFP/AAP Workshop on Periodontitis and Systemic Diseases. J Clin Periodontol 2013, 40 Suppl 14:S106-112.

13. Gui MJ, Dashper SG, Slakeski N, Chen YY, Reynolds EC: Spheres of influence: Porphyromonas gingivalis outer membrane vesicles. Mol Oral Microbiol 2016, 31(5):365-378.

14. Sayehmiri F, Sayehmiri K, Asadollahi K, Soroush S, Bogdanovic L, Jalilian FA, Emaneini M, Taherikalani M: The prevalence rate of Porphyromonas gingivalis and its association with cancer: $\mathrm{A}$ systematic review and meta-analysis. Int J Immunopathol Pharmacol 2015, 28(2):160-167.

15. Gupta B, Kumar N, Johnson NW: Periodontitis, oral hygiene habits, and risk of upper aerodigestive tract cancers: a case-control study in Maharashtra, India. Oral Surg Oral Med Oral Pathol Oral Radiol 2020.

16. Gupta B, Bray F, Kumar N, Johnson NW: Associations between oral hygiene habits, diet, tobacco and alcohol and risk of oral cancer: A case-control study from India. Cancer Epidemio/2017, 51:7-14.

17. Kawakita D, Lee YA, Li Q, Chen Y, Chen CJ, Hsu WL, Lou PJ, Zhu C, Pan J, Shen H et al: Impact of oral hygiene on head and neck cancer risk in a Chinese population. Head Neck 2017, 39(12):2549-2557.

18. Hashim D, Sartori S, Brennan P, Curado MP, Wunsch-Filho V, Divaris K, Olshan AF, Zevallos JP, Winn DM, Franceschi $S$ et al: The role of oral hygiene in head and neck cancer: results from International Head and Neck Cancer Epidemiology (INHANCE) consortium. Ann Oncol2016, 27(8):1619-1625. 
19. Gupta B, Kumar N, Johnson NW: Evidence of past dental visits and incidence of head and neck cancers: a systematic review and meta-analysis. Syst Rev 2019, 8(1):43.

20. Kim MK, Han K, Koh ES, Kim HS, Kwon HS, Park YM, Yoon KH, Lee SH: Variability in Total Cholesterol Is Associated With the Risk of End-Stage Renal Disease: A Nationwide Population-Based Study. Arterioscler Thromb Vasc Biol 2017, 37(10):1963-1970.

21. Song SO, Jung CH, Song YD, Park CY, Kwon HS, Cha BS, Park JY, Lee KU, Ko KS, Lee BW: Background and data configuration process of a nationwide population-based study using the korean national health insurance system. Diabetes Metab J 2014, 38(5):395-403.

22. Seong SC, Kim YY, Park SK, Khang YH, Kim HC, Park JH, Kang HJ, Do CH, Song JS, Lee EJ et al: Cohort profile: the National Health Insurance Service-National Health Screening Cohort (NHIS-HEALS) in Korea. BMJ Open 2017, 7(9):e016640.

23. Park SY, Kim SH, Kang SH, Yoon CH, Lee HJ, Yun PY, Youn TJ, Chae IH: Improved oral hygiene care attenuates the cardiovascular risk of oral health disease: a population-based study from Korea. Eur Heart J 2019, 40(14):1138-1145.

24. Lee JH, Choi JK, Jeong SN, Choi SH: Charlson comorbidity index as a predictor of periodontal disease in elderly participants. J Periodontal Implant Sci 2018, 48(2):92-102.

25. Lee JH, Lee JS, Park JY, Choi JK, Kim DW, Kim YT, Choi SH: Association of Lifestyle-Related Comorbidities With Periodontitis: A Nationwide Cohort Study in Korea. Medicine (Baltimore) 2015, 94(37):e1567.

26. Hashibe M, Brennan P, Benhamou S, Castellsague X, Chen C, Curado MP, Dal Maso L, Daudt AW, Fabianova E, Fernandez $L$ et al: Alcohol drinking in never users of tobacco, cigarette smoking in never drinkers, and the risk of head and neck cancer: pooled analysis in the International Head and Neck Cancer Epidemiology Consortium. J Natl Cancer Inst 2007, 99(10):777-789.

27. Seo HJ, Oh IH, Yoon SJ: A comparison of the cancer incidence rates between the national cancer registry and insurance claims data in Korea. Asian Pac J Cancer Prev 2012, 13(12):6163-6168.

28. Maier H, Zoller J, Herrmann A, Kreiss M, Heller WD: Dental status and oral hygiene in patients with head and neck cancer. Otolaryngol Head Neck Surg 1993, 108(6):655-661.

29. Zeng XT, Leng WD, Zhang C, Liu J, Cao SY, Huang W: Meta-analysis on the association between toothbrushing and head and neck cancer. Oral Oncol 2015, 51(5):446-451.

30. Velly AM, Franco EL, Schlecht N, Pintos J, Kowalski LP, Oliveira BV, Curado MP: Relationship between dental factors and risk of upper aerodigestive tract cancer. Oral Oncol 1998, 34(4):284-291.

31. Zheng TZ, Boyle P, Hu HF, Duan J, Jian PJ, Ma DQ, Shui LP, Niu SR, Scully C, MacMahon B: Dentition, oral hygiene, and risk of oral cancer: a case-control study in Beijing, People's Republic of China. Cancer Causes Control 1990, 1(3):235-241.

32. Moreno-Lopez LA, Esparza-Gomez GC, Gonzalez-Navarro A, Cerero-Lapiedra R, Gonzalez-Hernandez MJ, Dominguez-Rojas V: Risk of oral cancer associated with tobacco smoking, alcohol consumption and oral hygiene: a case-control study in Madrid, Spain. Oral Oncol2000, 36(2):170-174. 
33. Wang RS, Hu XY, Gu WJ, Hu Z, Wei B: Tooth loss and risk of head and neck cancer: a meta-analysis. PLoS One 2013, 8(8):e71122.

34. Shi J, Leng W, Zhao L, Deng C, Xu C, Wang J, Wang Y, Peng X: Tooth loss and cancer risk: a doseresponse meta analysis of prospective cohort studies. Oncotarget 2018, 9(19):15090-15100.

35. Abnet CC, Qiao YL, Mark SD, Dong ZW, Taylor PR, Dawsey SM: Prospective study of tooth loss and incident esophageal and gastric cancers in China. Cancer Causes Control 2001, 12(9):847-854.

36. Simila T, Virtanen Jl: Association between smoking intensity and duration and tooth loss among Finnish middle-aged adults: The Northern Finland Birth Cohort 1966 Project. BMC Public Health $2015,15: 1141$.

37. Gankhuyag N, Lee KH, Cho JY: The Role of Nitrosamine (NNK) in Breast Cancer Carcinogenesis. J Mammary Gland Biol Neoplasia 2017, 22(3):159-170.

38. Multhoff G, Molls M, Radons J: Chronic inflammation in cancer development. Front Immuno/2011, 2:98.

39. Rosenquist K, Wennerberg J, Schildt EB, Bladstrom A, Goran Hansson B, Andersson G: Oral status, oral infections and some lifestyle factors as risk factors for oral and oropharyngeal squamous cell carcinoma. A population-based case-control study in southern Sweden. Acta Otolaryngo/ 2005, 125(12):1327-1336.

40. Balaram P, Sridhar H, Rajkumar T, Vaccarella S, Herrero R, Nandakumar A, Ravichandran K, Ramdas $\mathrm{K}$, Sankaranarayanan R, Gajalakshmi V et al: Oral cancer in southern India: the influence of smoking, drinking, paan-chewing and oral hygiene. Int J Cancer 2002, 98(3):440-445.

41. Caton JG, Armitage G, Berglundh T, Chapple ILC, Jepsen S, Kornman KS, Mealey BL, Papapanou PN, Sanz M, Tonetti MS: A new classification scheme for periodontal and peri-implant diseases and conditions - Introduction and key changes from the 1999 classification. $J$ Periodontol 2018, 89 Suppl 1:S1-S8.

\section{Tables}


Table 1. Baseline characteristics of the study population.

\begin{tabular}{|c|c|}
\hline Characteristics & Total \\
\hline Number of subjects & 150,774 \\
\hline Age (years) & $52.2 \pm 8.7$ \\
\hline Male sex & $91,855(60.9)$ \\
\hline \multicolumn{2}{|l|}{ Income levels } \\
\hline Fifth quintile (highest) & $59,339(39.4)$ \\
\hline Fourth quintile & $30,701(20.4)$ \\
\hline Third quintile & $20,871(13.8)$ \\
\hline Second quintile & $18,962(12.6)$ \\
\hline First quintile (lowest) & 20,665 (13.7) \\
\hline Covered by medical aid & $236(0.2)$ \\
\hline Alcohol intake & $71,800(47.6)$ \\
\hline \multicolumn{2}{|l|}{ Smoking status } \\
\hline Never smoker & $97,037(64.4)$ \\
\hline Former smoker & $15,590(10.3)$ \\
\hline Current smoker & $38,147(25.3)$ \\
\hline Regular physical activity & $14,570(9.7)$ \\
\hline \multicolumn{2}{|l|}{ Anthropometric measurements } \\
\hline Body mass index $\left(\mathrm{kg} / \mathrm{m}^{2}\right)$ & $23.9 \pm 2.9$ \\
\hline Systolic blood pressure (mmHg) & $126.4 \pm 17.2$ \\
\hline Diastolic blood pressure (mmHg) & $79.4 \pm 11.2$ \\
\hline \multicolumn{2}{|l|}{ Comorbidities } \\
\hline Hypertension & $59,234(39.3)$ \\
\hline Diabetes mellitus & $13,609(9.0)$ \\
\hline Dyslipidaemia & 24,027 (15.9) \\
\hline \multicolumn{2}{|l|}{ Laboratory findings } \\
\hline Total cholesterol (mg/dL) & $198.2 \pm 36.4$ \\
\hline Fasting blood sugar (mg/dL) & $97.0 \pm 29.0$ \\
\hline Aspartate aminotransferase (U/L) & $26.0 \pm 16.0$ \\
\hline Alanine aminotransferase (U/L) & $25.4 \pm 19.8$ \\
\hline Gamma glutamyl transferase (U/L) & $38.3 \pm 53.0$ \\
\hline Proteinuria ( $\geq 1+$ in dipstick test) & $4,495(3.0)$ \\
\hline \multicolumn{2}{|l|}{ Oral hygiene care } \\
\hline \multicolumn{2}{|l|}{ Tooth brushing (times/day) } \\
\hline $0-1$ & $22,111(14.7)$ \\
\hline 2 & $67,502(44.8)$ \\
\hline$\geq 3$ & $61,161(40.6)$ \\
\hline Dental visit for any reason & $63,506(42.1)$ \\
\hline Expertised dental cleaning & $35,859(23.8)$ \\
\hline \multicolumn{2}{|l|}{ Oral health status } \\
\hline Periodontal disease & $19,861(13.1)$ \\
\hline \multicolumn{2}{|l|}{ Number of tooth loss } \\
\hline 0 & $114,459(75.9)$ \\
\hline $1-7$ & $32,545(21.6)$ \\
\hline $8-14$ & $2,235(1.5)$ \\
\hline$\geq 15$ & $1,535(1.0)$ \\
\hline
\end{tabular}

Data are expressed as the mean $\pm \mathrm{SD}$, or $\mathrm{n}(\%)$. 
Table 2. Risk of head and neck cancer based on periodontal disease and parameters of oral health.

Page $14 / 17$ 


\begin{tabular}{|c|c|c|c|c|c|c|c|c|c|c|c|c|c|c|}
\hline & \multirow[t]{2}{*}{$\begin{array}{c}\text { No. of } \\
\text { subjects }\end{array}$} & \multirow[t]{2}{*}{$\begin{array}{l}\text { No. of } \\
\text { events }\end{array}$} & \multirow{2}{*}{$\begin{array}{l}\text { Follow- } \\
\text { up } \\
\text { duration } \\
\text { (person- } \\
\text { years) }\end{array}$} & \multirow{2}{*}{$\begin{array}{c}\text { Age- } \\
\text { adjusted } \\
\text { incidence } \\
\text { rate } \\
\text { (per } 1000 \\
\text { person-yrs, } \\
(95 \% \mathrm{CI}))\end{array}$} & \multicolumn{2}{|c|}{$\begin{array}{l}\text { Unadjusted } \\
\text { model }\end{array}$} & \multicolumn{2}{|c|}{$\begin{array}{l}\text { Age, sex- } \\
\text { adjusted } \\
\text { model }\end{array}$} & \multicolumn{2}{|c|}{$\begin{array}{c}\text { Multivariable } \\
\text { model } 1\end{array}$} & \multicolumn{2}{|c|}{$\begin{array}{l}\text { Multivariable } \\
\text { model } 2\end{array}$} & \multicolumn{2}{|c|}{$\begin{array}{c}\text { Multivariable } \\
\text { model } 3\end{array}$} \\
\hline & & & & & $\begin{array}{c}\text { HR } \\
(95 \% \\
\text { CI) }\end{array}$ & $\begin{array}{c}\mathrm{P}- \\
\text { value }\end{array}$ & $\begin{array}{c}\text { HR } \\
(95 \% \\
\text { CI) }\end{array}$ & $\begin{array}{c}\mathrm{P}- \\
\text { value }\end{array}$ & $\begin{array}{c}\text { HR } \\
(95 \% \\
\text { CI })\end{array}$ & $\begin{array}{c}\mathrm{P}- \\
\text { value }\end{array}$ & $\begin{array}{c}\text { HR } \\
(95 \% \\
\text { CI) }\end{array}$ & $\begin{array}{c}\text { P- } \\
\text { value }\end{array}$ & $\begin{array}{c}\mathrm{HR} \\
(95 \% \\
\mathrm{CI})\end{array}$ & $\begin{array}{c}\text { P- } \\
\text { value }\end{array}$ \\
\hline \multicolumn{15}{|c|}{$\begin{array}{l}\text { Periodontal } \\
\text { disease }\end{array}$} \\
\hline No & 130913 & 1036 & 1499100 & $\begin{array}{c}0.52 \\
(0.49,0.56)\end{array}$ & $\begin{array}{c}1 \\
\text { (ref) }\end{array}$ & & $\begin{array}{c}1 \\
\text { (ref) }\end{array}$ & & $\begin{array}{c}1 \\
\text { (ref) }\end{array}$ & & $\begin{array}{c}1 \\
\text { (ref) }\end{array}$ & & $\begin{array}{c}1 \\
\text { (ref) }\end{array}$ & \\
\hline Yes & 19861 & 119 & 225247 & $\begin{array}{c}0.39 \\
(0.33,0.47)\end{array}$ & $\begin{array}{l}0.76 \\
(0.63 \\
0.92)\end{array}$ & 0.004 & $\begin{array}{l}0.78 \\
(0.65 \\
0.94)\end{array}$ & 0.011 & $\begin{array}{l}0.79 \\
(0.65 \\
1.02)\end{array}$ & 0.069 & $\begin{array}{l}0.79 \\
(0.66 \\
1.03)\end{array}$ & 0.066 & $\begin{array}{l}0.80 \\
(0.65 \\
1.03)\end{array}$ & 0.063 \\
\hline \multicolumn{15}{|c|}{$\begin{array}{l}\text { Frequency } \\
\text { of tooth } \\
\text { brushing } \\
\text { (times/day) }\end{array}$} \\
\hline 0-1 & 22111 & 240 & 248224 & $\begin{array}{c}0.59 \\
(0.52,0.68)\end{array}$ & $\begin{array}{c}1 \\
\text { (ref) }\end{array}$ & & $\begin{array}{c}1 \\
\text { (ref) }\end{array}$ & & $\begin{array}{c}1 \\
\text { (ref) }\end{array}$ & & $\begin{array}{c}1 \\
\text { (ref) }\end{array}$ & & $\begin{array}{c}1 \\
\text { (ref) }\end{array}$ & \\
\hline 2 & 67502 & 587 & 774302 & $\begin{array}{c}0.55 \\
(0.50,0.60)\end{array}$ & $\begin{array}{l}0.80 \\
(0.69 \\
0.93)\end{array}$ & 0.004 & $\begin{array}{l}0.90 \\
(0.78 \\
1.05)\end{array}$ & 0.185 & $\begin{array}{l}0.91 \\
(0.78 \\
1.06)\end{array}$ & 0.240 & $\begin{array}{l}0.92 \\
(0.79 \\
1.07)\end{array}$ & 0.263 & $\begin{array}{l}0.94 \\
(0.80 \\
1.09)\end{array}$ & 0.397 \\
\hline$\geq 3$ & 61161 & 328 & 701821 & $\begin{array}{c}0.43 \\
(0.38,0.48)\end{array}$ & $\begin{array}{l}0.49 \\
(0.42 \\
0.58)\end{array}$ & $<.001$ & $\begin{array}{l}0.72 \\
(0.61 \\
0.85)\end{array}$ & 0.001 & $\begin{array}{l}0.75 \\
(0.64 \\
0.89)\end{array}$ & 0.001 & $\begin{array}{c}0.76 \\
(0.64 \\
0.90)\end{array}$ & 0.002 & $\begin{array}{l}0.79 \\
(0.66 \\
0.94)\end{array}$ & 0.007 \\
\hline $\begin{array}{l}\text { P for } \\
\text { trend* }\end{array}$ & & & & & $<.001$ & & $<.001$ & & $<.001$ & & 0.001 & & 0.005 & \\
\hline \multicolumn{15}{|c|}{$\begin{array}{l}\text { Dental visit } \\
\text { for any } \\
\text { reason }\end{array}$} \\
\hline No & 87268 & 703 & 995817 & $\begin{array}{c}0.52 \\
(0.48,0.57)\end{array}$ & $\begin{array}{c}1 \\
\text { (ref) }\end{array}$ & & $\begin{array}{c}1 \\
\text { (ref) }\end{array}$ & & $\begin{array}{c}1 \\
\text { (ref) }\end{array}$ & & $\begin{array}{c}1 \\
\text { (ref) }\end{array}$ & & $\begin{array}{c}1 \\
\text { (ref) }\end{array}$ & \\
\hline Yes & 63506 & 452 & 728530 & $\begin{array}{c}0.49 \\
(0.44,0.54)\end{array}$ & $\begin{array}{l}0.88 \\
(0.79 \\
0.99)\end{array}$ & 0.040 & $\begin{array}{l}0.98 \\
(0.87 \\
1.10)\end{array}$ & 0.681 & $\begin{array}{l}0.99 \\
(0.88 \\
1.12)\end{array}$ & 0.928 & $\begin{array}{l}1.00 \\
(0.89 \\
1.12)\end{array}$ & 0.949 & $\begin{array}{l}1.06 \\
(0.93 \\
1.21)\end{array}$ & 0.377 \\
\hline \multicolumn{15}{|c|}{$\begin{array}{l}\text { Expertised } \\
\text { dental } \\
\text { cleaning }\end{array}$} \\
\hline No & 114915 & 960 & 1311583 & $\begin{array}{c}0.53 \\
(0.49,0.57)\end{array}$ & $\begin{array}{c}1 \\
\text { (ref) }\end{array}$ & & $\begin{array}{c}1 \\
\text { (ref) }\end{array}$ & & $\begin{array}{c}1 \\
\text { (ref) }\end{array}$ & & $\begin{array}{c}1 \\
\text { (ref) }\end{array}$ & & $\begin{array}{c}1 \\
\text { (ref) }\end{array}$ & \\
\hline Yes & 35859 & 195 & 412764 & $\begin{array}{c}0.44 \\
(0.38,0.50)\end{array}$ & $\begin{array}{l}0.65 \\
(0.56 \\
0.76)\end{array}$ & $<.001$ & $\begin{array}{l}0.86 \\
(0.73 \\
1.00)\end{array}$ & 0.050 & $\begin{array}{l}0.89 \\
(0.76 \\
1.04)\end{array}$ & 0.133 & $\begin{array}{l}0.89 \\
(0.76 \\
1.04)\end{array}$ & 0.144 & $\begin{array}{l}0.91 \\
(0.77 \\
1.08)\end{array}$ & 0.295 \\
\hline \multicolumn{15}{|c|}{$\begin{array}{l}\text { Number of } \\
\text { tooth loss }\end{array}$} \\
\hline 0 & 114459 & 749 & 1314108 & $\begin{array}{c}0.47 \\
(0.43,0.51)\end{array}$ & $\begin{array}{c}1 \\
\text { (ref) }\end{array}$ & & $\begin{array}{c}1 \\
\text { (ref) }\end{array}$ & & $\begin{array}{c}1 \\
\text { (ref) }\end{array}$ & & $\begin{array}{c}1 \\
\text { (ref) }\end{array}$ & & $\begin{array}{c}1 \\
\text { (ref) }\end{array}$ & \\
\hline $1-7$ & 32545 & 313 & 370227 & $\begin{array}{c}0.61 \\
(0.54,0.69)\end{array}$ & $\begin{array}{l}1.47 \\
(1.29 \\
1.68)\end{array}$ & $<.001$ & $\begin{array}{l}1.34 \\
(1.17 \\
1.53)\end{array}$ & $<.001$ & $\begin{array}{l}1.30 \\
(1.14 \\
1.48)\end{array}$ & 0.001 & $\begin{array}{l}1.30 \\
(1.13 \\
1.48)\end{array}$ & $<.001$ & $\begin{array}{l}1.29 \\
(1.12 \\
1.47)\end{array}$ & $<.001$ \\
\hline $8-14$ & 2235 & 44 & 24295 & $\begin{array}{c}0.75 \\
(0.55,1.01)\end{array}$ & $\begin{array}{l}3.02 \\
(2.23 \\
4.10)\end{array}$ & $<.001$ & $\begin{array}{l}1.56 \\
(1.15 \\
2.13)\end{array}$ & 0.005 & $\begin{array}{l}1.51 \\
(1.11 \\
2.06)\end{array}$ & 0.009 & $\begin{array}{l}1.49 \\
(1.10 \\
2.04)\end{array}$ & 0.011 & $\begin{array}{l}1.47 \\
(1.08 \\
2.01)\end{array}$ & 0.015 \\
\hline$\geq 15$ & 1535 & 49 & 15717 & $\begin{array}{c}0.88 \\
(0.65,1.19)\end{array}$ & $\begin{array}{l}4.93 \\
(3.69 \\
6.59)\end{array}$ & $<.001$ & $\begin{array}{l}1.73 \\
(1.28 \\
2.34)\end{array}$ & $<.001$ & $\begin{array}{l}1.71 \\
(1.26 \\
2.31)\end{array}$ & 0.001 & $\begin{array}{l}1.68 \\
(1.24 \\
2.28)\end{array}$ & $<.001$ & $\begin{array}{c}1.66 \\
(1.22 \\
2.25)\end{array}$ & 0.001 \\
\hline $\begin{array}{l}\text { P for } \\
\text { trend* }\end{array}$ & & & & & $<.001$ & & $<.001$ & & $<.001$ & & $<.001$ & & $<.001$ & \\
\hline
\end{tabular}


Multivariable model 1 was adjusted for age, sex, income level, alcohol intake, smoking status, regular exercise, body mass index $\left(\mathrm{kg} / \mathrm{m}^{2}\right)$, hypertension, diabetes, and dyslipidemia.

Multivariable model 2 was adjusted for the variables listed above as well as systolic blood pressure, total cholesterol, fasting blood sugar, aspartate aminotransferase, alanine aminotransferase, gamma glutamyl transpeptidase, and proteinuria.

Multivariable model 3 was adjusted for the variables listed above as well as periodontal disease, frequency of tooth brushing, dental visit for any reason, expertised dental cleaning, and number of tooth loss.

CI, confidence interval; HR, hazard ratio.

*: The trend test for hazard ratios

Multivariable analysis was performed by using regression methods of Fine and Gray for competing risk data (death is a competing event for head and neck cancer).

\section{Figures}

\begin{tabular}{|c|}
\hline $\begin{array}{c}\text { Subjects who received health } \\
\text { screening between } 2003 \text { and } 2004 \\
\mathrm{~N}=514,866\end{array}$ \\
\hline $\begin{array}{c}\text { Demographic data, income data, } \\
\text { claim data, eligibility status and death } \\
\text { records by the end of } 2013\end{array}$ \\
\hline
\end{tabular}

$$
\begin{aligned}
& \text { Missing data in oral health status } \\
& \text { between } 2003 \text { and } 2004 \\
& N=343,037
\end{aligned}
$$

$$
\begin{aligned}
& \text { Missing data in health examination } \\
& \qquad N=8,094
\end{aligned}
$$

\section{History of malignancy before the examination day for oral health status \\ $\mathrm{N}=12,961$}

Finally,

150,774 subjects were enrolled 
Figure 1

Flow chart of the study subjects.
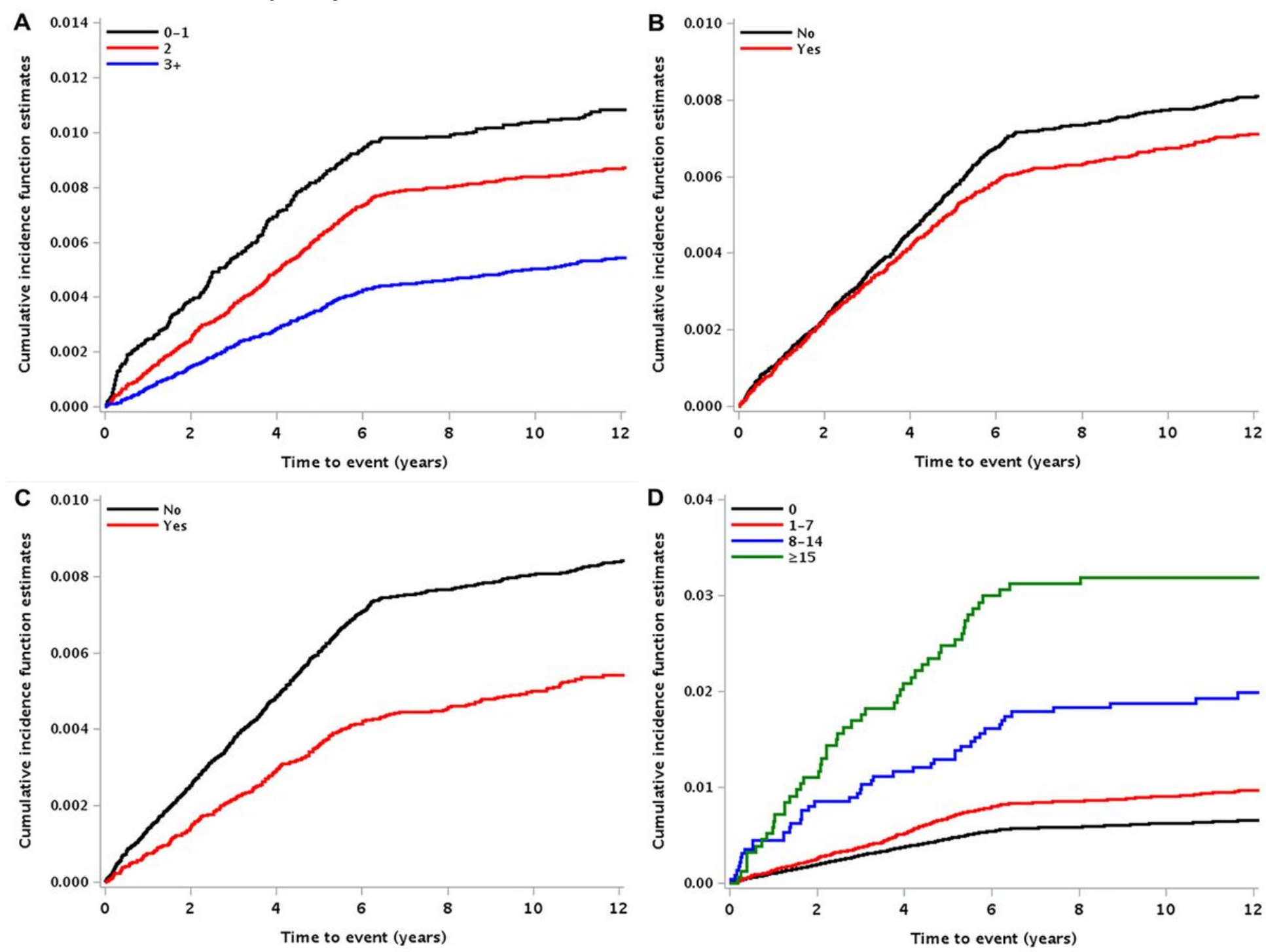

Figure 2

The cumulative incidence curves which analyzed by Gray's Test for the association of parameters of oral health with occurrence of head and neck cancer. Cumulative incidence curves show that risk of head and neck cancer depends on the frequency of tooth brushings $(A)(p<0.001)$, dental visit for any reason (B) (p $=0.040)$, expertised dental cleaning $(C)(p<0.001)$, and number of tooth loss $(D)(p<0.001)$.

\section{Supplementary Files}

This is a list of supplementary files associated with this preprint. Click to download.

- Additionalfile1plain.doc 